\title{
Erlotinib in Patients with Previously Irradiated, Recurrent Brain Metastases from Non-Small Cell Lung Cancer: Two Case Reports
}

\author{
Joachim von Pawel ${ }^{\mathrm{a}} \quad$ Horst Wagner $^{\mathrm{a}} \quad$ Thomas Duella ${ }^{\mathrm{a}}$ Barbara Poellinger ${ }^{\mathrm{b}}$ \\ ${ }^{a}$ Klinik für Pneumologie, Asklepios-Fachkliniken München-Gauting, \\ ${ }^{\mathrm{b}}$ Klinik für Strahlentherapie und Radioonkologie, Ludwig Maximilians Universität München, Germany
}

Key Words

NSCLC · EGFR inhibition · Erlotinib · Brain metastases

\section{Summary}

Background: With the current improvements in primary lung care, the long-term control of brain metastases becomes a clinical challenge. No established therapeutic approaches exist for cranial relapse after response to previous radiotherapy and systemic therapy. Tyrosine kinase inhibitors like erlotinib with its proven activity in non-small cell lung cancer may provide clinical benefits in such patients. Patients and Methods: Two case reports are presented illustrating the efficacy of erlotinib in patients with recurrent brain metastases and parallel thoracic progression. Results: Both patients showed lasting partial remissions in the brain and lung, and clinical symptom improvement. Conclusion: The observed survival times of above 18 and 15 months, respectively, since occurrence of cranial disease manifestation in line with the achieved progression-free survival times of 9 and 6 months by the erlotinib third-line therapy are remarkable. The use of targeted therapies after wholebrain irradiation should be investigated more systematically in prospective clinical trials.

\section{Introduction}

Brain metastases are a common feature of lung cancer, and are gaining more and more attention as combined modality treatment and efficient new drug therapies have improved local control and overall survival rates. Brain metastases from
Schlüisselwörter

NSCLC · EGFR-Inhibition · Erlotinib · Hirnmetastasen

\section{Zusammenfassung}

Hintergrund: Trotz verbesserter Behandlungsmöglichkeiten bei Lungenkarzinomen stellt sich die adäquate Behandlung von Hirnmetastasen als schwierig dar. Insbesondere bei kranialer Rezidivbildung nach Ganzhirnbestrahlung und vorangegangener Chemotherapie fehlen jegliche Therapieoptionen. Tyrosinkinase-Inhibitoren wie Erlotinib mit seiner etablierten Aktivität beim nicht-kleinzelligen Lungenkarzinom können bei dieser Patientenpopulation eine zusätzliche Therapieoption darstellen. Patienten und Methoden: Diese Arbeit stellt 2 gleichartige Kasuistiken vor und beschreibt die Ergebnisse eines solchen Ansatzes. Ergebnisse: Beide Patienten zeigten anhaltende kraniale und pulmonale Remissionen bei gleichzeitiger Symptomverbesserung. Schlussfolgerung: Die beobachteten Überlebenszeiten von 18 bzw. 15 Monaten seit Auftreten der Hirnmetastasen sowie ein progressionsfreies Überleben von 9 bzw. 6 Monaten sind bemerkenswert. Eine weitergehende Untersuchung des Einsatzes so genannter "targeted therapies" nach erfolgter Ganzhirnbestrahlung erscheint viel versprechend.

\begin{tabular}{ll}
\hline KARGER & ๑ 2008 S. Karger GmbH, Freiburg \\
$\begin{array}{l}\text { Fax +49761 45207 14 } \\
\begin{array}{l}\text { E-mail Information@Karger.de } \\
\text { www.karger.com }\end{array}\end{array}$ & $\begin{array}{l}\text { Accessible online at: } \\
\text { www.karger.com/onk }\end{array}$
\end{tabular}

\section{KARGER}

www.karger.com lung cancer are the most common type of intracranial neoplasm. $20-40 \%$ of patients with non-small cell lung cancer (NSCLC) develop CNS metastases at some point in the course of their disease [1]. Radiotherapy remains the cornerstone of treatment for NSCLC patients with brain metastases: Whole-brain radiotherapy (WBRT) is the accepted standard 
therapy in patients with multiple metastases - a pattern often associated with metastasizing lung cancer [2]. However, patients treated with WBRT show, despite acceptable overall response rates (ORR) of $60 \%$, an unsatisfying outcome with high rates of recurrent disease. Apart from patients with favorable prognostic factors belonging to recursive partitioning analysis (RPA) class I and considered as candidates for local curative therapy approaches, the majority of patients has a poor diagnosis with a median survival of about 3-4 months [3, 4]. In the case of recurrent brain metastases, no standard therapeutic options exist. Because recurrent brain metastases are indicators of very limited survival and decreasing performance status, therapeutic alternatives such as stereotactic radiosurgery (SRS) for single metastases are urgently needed [5]. WBRT may qualify as a therapeutic alternative in cases where surgical resection or SRS were used before as front-line approaches for local control [6]. Chemotherapy as a salvage option after WBRT has been investigated in a number of trials; only modest activity has been observed in patients with recurrent brain metastases from various malignancies [7, 8]. In a phase II trial investigating oral tyrosine kinase (TK) inhibitor gefitinib, 18 previously irradiated patients (WBRT completed 3 months before enrolment) drew a clinical benefit from therapy: the disease-control rate was significantly improved, and the progression-free survival prolonged (4 vs. 2 months). 4 objective cranial remissions (ORR 10\%) were reported [9]. 2 Japanese case series describing their clinical experience on gefitinib-treated brain metastases (14 and 15 patients, respectively) also included single reports of treatment benefits in recurrent cranial disease [10,11].

For the oral epidermal growth factor receptor (EGFR) TK inhibitor erlotinib, no experiences except 1 casuistic report documenting a complete cerebral response in a patient with recurrent brain metastases after WBRT and second-line chemotherapy, have been published [12]. Here, we report the outcome of 2 patients with recurrent brain metastases after WBRT and subsequent chemotherapy, who received erlotinib monotherapy as a salvage therapy.

\section{Patients and Materials}

Since the end of 2004, erlotinib has been routinely used in our hospital. Prior to its marketing authorization in autumn 2005, the drug was provided by the manufacturer via an expanded access program. Until spring 2006, approximately 150 patients who failed standard first-line combination therapy received oral erlotinib in accordance with the prescribing information. Encouraging results in patients with brain metastases led to a retrospective analysis of cases who received erlotinib after previous cranial radiation. The 2 selected cases were the ones in which new cranial as well as thoracic progression were observed after WBRT. Patients underwent systematic control examinations every month including a complete blood count, the standard clinical chemistry, serum creatinine, and liver function tests. Radiological controls of the primary tumor were done monthly and completed by bimonthly magnetic resonance imaging and computer tomography controls for thoracic and cranial disease and, if ap-
Table 1. Patient demographics for both cases receiving erlotinib salvage therapy

\begin{tabular}{|c|c|c|}
\hline & Case 1 (Patient A) & Case 2 (Patient B) \\
\hline Age and gender & 40-year-old woman & 63-year-old woman \\
\hline Histology & adenocarcinoma & adenocarcinoma \\
\hline Smoking status & nicotine abuse until 1992 & non-smoker \\
\hline $\begin{array}{l}\text { TNM stage (first } \\
\text { diagnosis) }\end{array}$ & IV (T3N3M1 G3) & IV (pT2N0M1) \\
\hline Radiotherapy (WBRT) & $\begin{array}{l}40 \text { Gy ( } 46 \text { Gy boost left- } \\
\text { occipital) }\end{array}$ & 40 Gy \\
\hline Prognostic RPA class [3] & II & II \\
\hline
\end{tabular}

WBRT: Whole-brain radiotherapy: RPA: recursive partitioning analysis.

plicable, by adequate imaging techniques for other sites of metastatic disease manifestation. RECIST criteria were applied to assess complete responses (CR), partial responses (PR), stable disease (SD), and progressive disease (PD) [13]. Respiratory function testing was systematically carried out at time of therapy start and in monthly intervals. Disease-related symptoms were recorded using the National Cancer Institute's (NCI) grading system for adverse events.

\section{Results}

Table 1 summarizes the patient characteristics and major treatment outcomes. Both patients had a comparable prognostic profile in terms of gender, histology, disease stage, and RPA class at the time of cranial disease manifestation. In both patients, cranial disease manifestation occurred after a successfully completed first-line therapy. As both patients did not require rapid relief of intracranial pressure by surgical means, WBRT was the option of choice. The subsequent treatment sequence and the therapy results for Patient A (multiple brain metastases - the most prominent one left-sided occipital) and Patient B (singular lesion right-sided temporal) are presented in figure 1.

Tumor relapse after WBRT resulted for Patient A in the occurrence of new cranial lesions with further increase in number and size after second-line chemotherapy. Parallel thoracic progress, the occurrence of 2 hepatic and of osseous lesions (lumbar vertebrae and ribs) and an impressive rise of tumor marker CEA completed the picture of a general clinical deterioration. As a promising therapeutic alternative with a proven survival benefit in late-stage NSCLC patients, erlotinib therapy was commenced in July 2005. Figure 2 depicts the excellent radiological response in the chest and brain. Due to new hepatic progression in April 2006, erlotinib therapy was stopped 2 weeks later despite ongoing cranial and thoracic remission. The patient died in May 2006 following general disease progression.

In Patient B, recurrent tumor progression after WBRT and second-line therapy was documented with increased thoracic tumor infiltration, hepatic tumor manifestation and cranial re- 


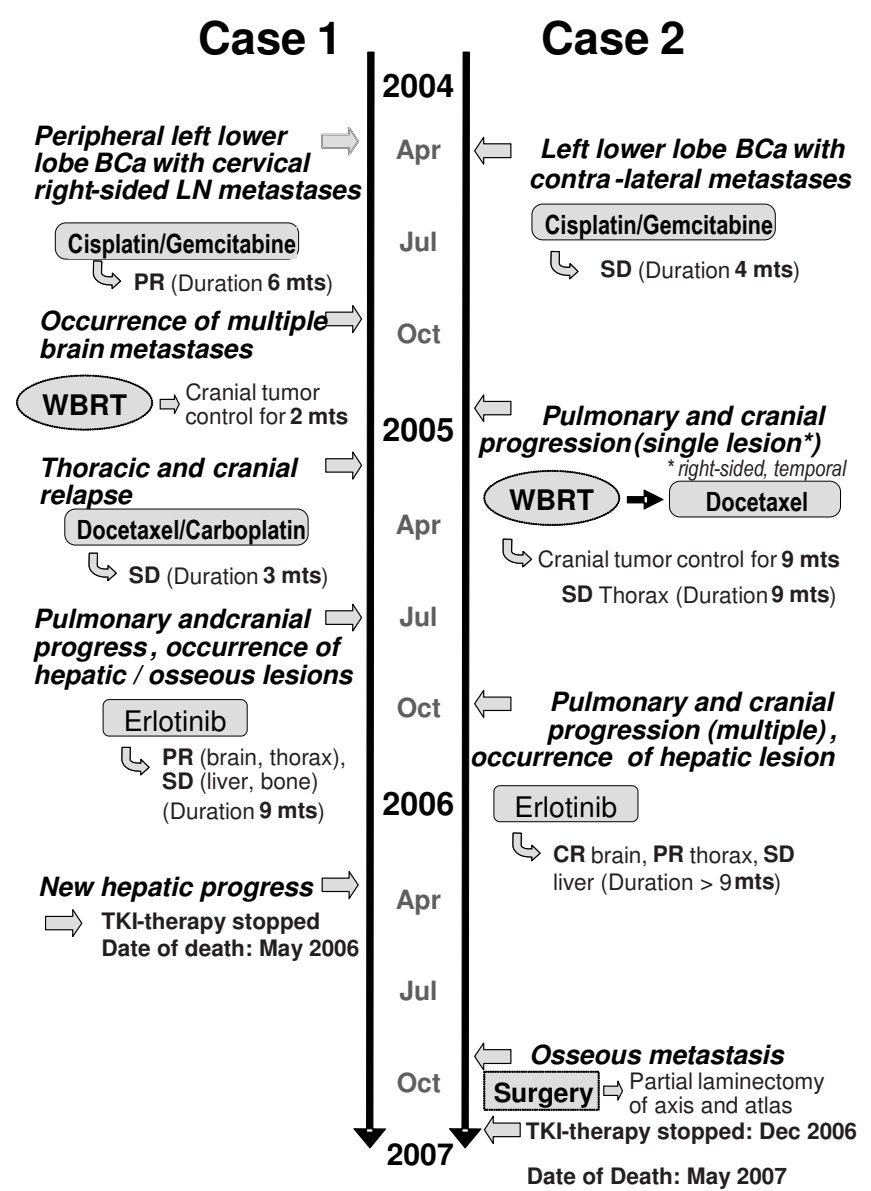

Fig. 1. Schematic presentation of both cases, indicating the pattern of progression, the principal therapeutic interventions, and the treatment outcomes $(\mathrm{BCa}=$ Bronchial carcinoma; $\mathrm{CR}=$ complete response; $\mathrm{PR}=$ partial response; $\mathrm{SD}=$ stable disease; $\mathrm{LN}=$ lymph node; $\mathrm{mts}=$ months; $\mathrm{TKI}=$ tyrosine kinase inhibition; WBRT $=$ whole-brain radiotherapy).

lapse. 3 new intracerebral metastases (parieto-occipital, right frontal, and left occipital) were detected after a 9-month period of disease stabilization. Erlotinib therapy started in October 2005 and resulted in almost CR in the brain as well as in the disappearance of the diffuse thoracic infiltration (images not shown). The lasting objective remission of above 9 months was accompanied by an impressive clinical remission with a remarkable amelioration of dyspnea, cough, chest pain, loss of appetite, and headaches. Erlotinib was stopped in December 2006 after occurrence of osseous metastases requiring partial laminectomy of the axis and the atlas. The patient died in May 2007 after further disease progression.

Apart from single episodes of infection, no adverse events were recorded in both patients except mild to moderate rash, well known as a class effect of EGFR inhibitors. Hematology results were normal, for clinical chemistry slightly elevated liver transaminase levels (grade I toxicity SGOT, AP, and GGT) were observed in both cases. Fixed-dose corticoid therapy was maintained during erlotinib therapy to control symptoms of vertigo in Patient A.

\section{CT Scan Chest}

\section{Before}

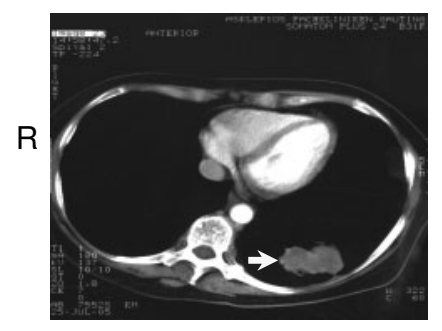

MRI Scans Brain Before

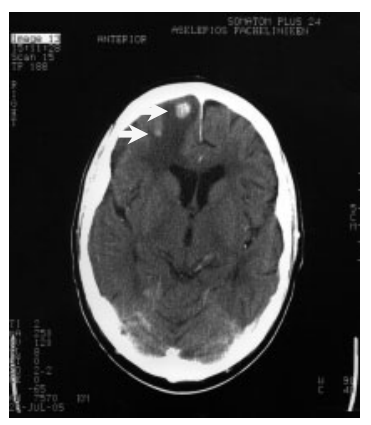

3 months after

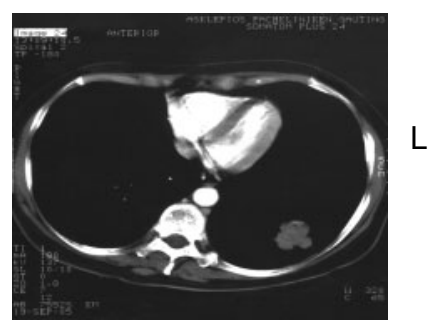

3 months after

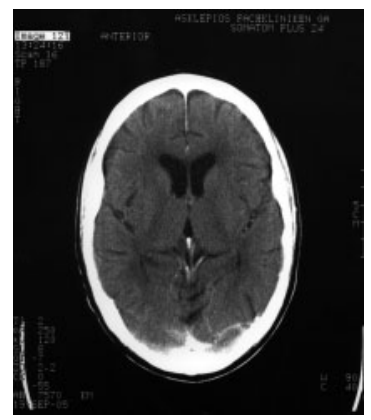

Fig. 2. Case 1. Response to erlotinib in the primary tumor and in the brain (case history shown in fig. 1).

\section{Discussion}

With the current improvements in primary lung care, the longterm control of brain metastases becomes a clinical need. The explorative use of systemic therapeutic options like chemotherapy or new biological agents like TK inhibitors is therefore required. The detection of rapid cerebral tumor progression after WBRT and the occurrence of peritumoral attendant edema, as observed in our patients, are signs of an already distorted blood-brain barrier in favor of drug therapy [14].

The observed objective remissions of the cerebral metastases in both cases are strong indicators for the clinical activity of TK inhibitors in such patients. Cases of simultaneous cerebral and thoracic tumor responses in recurrent disease that last for more than 6 months have been very rarely described in the literature. Simultaneous tumor responses after WBRT have not been described so far [9-11]. The possibility to control tumor progression in such different compartments is thought to affect survival. The availability of differing therapies itself is an option for survival prolongation as well.

A retrospective review of 4 SWOG studies with stage IIIA/B patients showed that the relapse in the brain and other sites compared to relapse in the brain alone resulted in shorter survival (4.5 vs. 10.3 months). Adenocarcinomas were shown to be overall more likely to fail in the brain [15]. On the other hand, adenocarcinoma histology and non-smoking are signifi- 
cant independent predictors of survival in erlotinib patients, as recently showed by exploratory multivariate analysis of a pivotal phase III trial [16]. These features may help to interpret the presented 2 clinical courses with noteworthy overall survival times of 18 and 15 months, respectively, since detection of brain metastasis. The achieved lasting symptom control in both patients - recurrent brain metastases are known to be usually symptomatic [17] - is of tremendous clinical value and deserves further investigation to understand the added value of TK inhibitors in the management of patients suffering from brain metastases.

\section{Conclusion}

The observed primary tumor shrinkage in addition to de-novo induction of objective remissions in brain metastases that reoccurred after initial WBRT requires attention. The observed survival times of above 18 and 15 months, respectively, since occurrence of cranial disease manifestation in line with the achieved lasting cranial and thoracic remission times and symptom control are noteworthy. The best sequential use of targeted therapies after WBRT should be investigated in prospective clinical trials.

\section{References}

1 Wen PY, McLaren Black P, Loeffler JS: Metastatic brain cancer; in De Vita JT, Hellmann S, Rosenberg SA (eds): Cancer: Principles and Practice of Oncology. 6th ed. Phialdelphia, Lippinscott, Williams and Wilkins, 1999, pp. 2655-2670.

2 Delattre Y, Krol G, Thaler HT, Posner JB: Distribution of brain metastases. Arch Neurol 1988;45 741-744.

3 Gaspar L, Scott C, Rotman M, Asbell S, Philipps T, Wasserman T, McKenna WG, Byhardt R: Recursive partitioning analysis (RPA) of prognostic factors in three Radiation Therapy Oncology Group (RTOG) brain metastases trials. Int J Radiat Oncol Biol Phys 1997;37:745-751.

4 Rodrigus P, de Brouwer P, Raaymakers E: Brain metastases and non-small cell lung cancer. Prognostic factors and correlation with survival after irradiation. Lung Cancer 2001;32:129-136.

5 Zabel A, Debus J: Treatment of brain metastases from non-small-cell lung cancer (NSCLC): radiotherapy. Lung Cancer 2004;45:S247-S252.

6 Khantia D, Brown P, Li J, Mehta MP: Whole-brain radiotherapy in the management of brain metastasis. J Clin Oncol 2006;24:1295-1304.

7 Abrey LE, Olson JD, Raizer JJ, Mack M, Rodavitch A, Boutros DY, Malkin MG: A phase II trial of temozolomide for patients with recurrent or progressive brain metastases. J Neurooncol 2001;53: 259-265.
8 Christodoulou C, Bafaloukos D, Kosmidis P, Samantas E, Bamias A, Papakostas P, Karabelis A, Bacoyiannis C, Skarlos DV, Hellenic Cooperative Oncology Group: Phase II study of temozolomide in heavily pretreated cancer patients with brain metastasis. Ann Oncol 2001;12:249-254.

9 Ceresoli GR, Capuzzo F, Gregorc V, Bartolini S, Crino L, Villa E: Gefitinib in patients with brain metastases from non-small cell lung cancer: a prospective trial. Ann Oncol 2004;15:1042-1047.

10 Hotta K, Kiura K, Ueoka H, Tabata M, Fujiwara K, Kozuki T, Okada T, Hisamoto A, Tanimoto M: Effect of gefitinib ('Iressa', ZD1839) on brain metastases in patients with advanced non-small cell lung cancer. Lung Cancer 2004;46:255-261.

11 Namba Y, Kijima T, Yokota S, Niinaka M, Kawamura S, Iwasaki T, Takeda Y, Kimura H, Okada T, Yamaguchi T, Okumura Y, Maeda H, Ito M: Gefitinib in patients with brain metastases from nonsmall-cell lung cancer: a review of 15 clinical cases. Clin Lung Cancer 2004;6:123-128.

12 Lai CS, Boshoff C: Complete response to erlotinib treatment in brain metastases from recurrent NSCLC. Thorax 2006;61:91.

13 Therasse P, Arbuck SG, Eisenhauer EA, Wanders J, Kaplan RS, Rubinstein L, Verweij J, van Glabbeke M, van Oosterom AT, Christian MC, Gwyther SG: New guidelines to evaluate the response to treatment in solid tumors. J Natl Cancer Inst 2000;92: 205-216.
14 Van den Bent MJ: The role of chemotherapy in brain metastases. Eur J Cancer 2003;39:2114-2120.

15 Gaspar LE, Chansky K, Albain KS, Vallieres E, Rusch V, Crowley J, Livingston R: Time from treatment to subsequent diagnosis of brain metastases in stage III non-small-cell lung cancer: a retrospective review by the SWOG. J Clin Oncol 2005;23: 2955-2961.

16 Shepherd F, Pereira JR, Ciuleanu T, Tan EH, Hirsh V, Thongprasert S, Campos d, Maoleekoonpiroj S, Smylie M, Martins R, van Kooten M, Dediu M, Findlay B, Tu D, Johnston D, Bezjak A, Clark G, Santabárbara P, Seymour L; National Cancer Institute of Canada Clinical Trials Group: Erlotinib in previously treated non-small-cell lung cancer. N Engl J Med 2005;353:123-132.

17 Regine WF, Huhn JL, Patchell RA, St Clair WH, Strottmann J, Meigooni A, Sanders M, Young AB Risk of symptomatic brain tumor recurrence and neurologic deficit after neurosurgery alone in patients with newly diagnosed brain metastases: results and implications. Int J Radiat Oncol Biol Phys 2002;53:333-338. 